\title{
Artigos
}

\section{O que crianças pensam sobre família e relações de gênero?}

Resumo: O artigo explora representações de crianças sobre família e relações de gênero. Trata-se de um novo tratamento dos dados de Gibim (2017), gerados com crianças usuárias de Educação Infantil. A partir de desenhos e narrativas de crianças, foi possível captar estereótipos de gênero oriundos de uma sociedade erguida em bases patriarcais, o que é refletido em práticas intrafamiliares que envolvem as crianças. Trata das transformações na unidade doméstica decorrentes, principalmente, da emergência de diferentes dinâmicas familiares e de um reposicionamento feminino decorrente do esgotamento do modelo tradicional conjugal. A Educação Infantil surge, neste contexto, no compartilhamento da educação e cuidado com as famílias, promovendo a redefinição dos papéis parentais na construção de contextos sociais livres de preconceitos.

Palavras-chave: Gênero. Famílias. Educação Infantil.

\section{What do children think about family and gender relations?}

Abstract: The paper explores children's representations about family and gender relations. This is a new treatment of Gibim's data (2017) produced with children who attend Early Childhood Education. From children's drawings and narratives, it was possible to capture gender stereotypes from a society built on patriarchal bases, which reflected in intrafamilial practices that involve children. It deals with transformations in the domestic unit, mainly due to the emergence of different family dynamics and a female repositioning resulting from the exhaustion of the traditional conjugal model. In this context, Early Childhood Education arises in the sharing of education and care with families, promoting the redefinition of parental roles in the construction of social contexts free of prejudice.

Key words: Gender. Families. Early Childhood Education.

\footnotetext{
1 Mestre em Educação pela Universidade Federal de São Paulo. E-mail: anapaulapggibim@gmail.com

2 Doutora em Educação pela Universidade Federal do Rio Grande do Sul. Professora Associada I da Universidade de Brasília. E-mail: fernandamuller@unb.com
} 


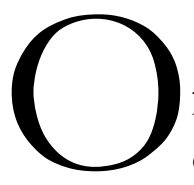

presente trabalho trata de diferentes dinâmicas familiares e relações de gênero a partir do ponto de vista de crianças, tendo em vista as condições socioeconômicas, políticas e culturais contemporâneas. Para tal reflexão, foram consideradas representações de crianças usuárias de Educação Infantil sobre suas famílias, por meio de seus desenhos e narrativas. As discussões apresentadas neste artigo atualizam e reinterpretam dados do trabalho de campo de Gibim (2017), realizado em uma instituição de Educação Infantil, e que, originalmente, abordou relações geracionais e de gênero nas famílias. Incorporamos a este artigo as perspectivas da sociologia da infância e dos estudos feministas e de gênero, buscando discutir as transformações e permanências que marcam as famílias e estas em relação à instituição de Educação Infantil.

A família, enquanto instituição social, é marcada pelas mesmas transformações que atravessam a sociedade. Castells (1999) e Therborn (2006) sugerem mudanças no contexto sociopolítico, econômico e cultural que têm transformado as famílias e tensionado os valores patriarcais ${ }^{3}$, que outrora regiam a organização familiar. Isso se deve, principalmente, ao empoderamento de mulheres, que modificou as relações intrafamiliares e possibilitou a construção de relações mais igualitárias e menos hierarquizadas. As mulheres, antes relegadas ao papel de guardiãs do lar, passaram a participar da vida pública, inseriram-se no mercado de trabalho e aumentaram seu poder; poder este que lhes tem garantido mais direitos e demandado uma reorganização do contrato familiar antes baseado em relações patriarcais.

Sociedades organizadas a partir de bases patriarcais preconizam relações sociais hierarquizadas por meio da desigual distribuição de poder entre homens e mulheres. Freyre (2006) mostra a configuração da sociedade brasileira a partir deste modelo de famillia. Segundo o autor, não se trata apenas de relações afetivas entre membros de uma unidade doméstica, mas de uma dimensão que se desdobra na organização política, econômica e social construída por meio de relações pautadas, principalmente, entre a casa grande e a senzala. Embora a família patriarcal tenha declinado significativamente enquanto modelo de organização (BERQUÓ, 1998; GIBIM, 2017), ainda permanece como autoridade moral e ideológica, regendo as relações sociais e concepções sobre a família (SARTI, 1992).

Já as instituições de Educação Infantil têm compartilhado com as famílias a responsabilidade com a educação e o cuidado de crianças pequenas. É um contexto que precisa atentar para as transformações sociais que modificam as relações intrafamiliares (PANIAGUA \& PALACIOS). Afinal, a superação da desigualdade também envolve o encontro de crianças e famílias em espaços coletivos na esfera pública, que tem o potencial de expô-las ao confronto e ao convívio com as diferenças (FINCO, 2015). Ainda,

3 O patriarcalismo consiste na autoridade institucionalmente imposta do homem sobre a mulher, e deste sobre os filhos (CASTELLS, 1999). 
Mayall (2010) afirma que as características do sistema de educação e de cuidado das crianças afetam diretamente as relações familiares. Práticas planejadas na Educação Infantil precisam considerar a família e a criança como interlocutoras, e promover trocas contínuas e recíprocas entre ambas as instituições, assim como acolher as representações de infância e crianças apresentadas pelas famílias "para inseri-las em um itinerário progressivo e compartilhado de desmistificação, de liberação de preconceitos e de concretização positiva" (FORTUNATI, 2009, p. 53).

Visando explorar representações de família e de gênero, procedemos à análise de desenhos e narrativas de crianças usuárias de Educação Infantil. A escuta às crianças ocorre por meio de um processo de coparticipação no qual elas podem comunicar representações sobre o seu mundo social (CRUZ, 2008; GOBBI, 2017). Pesquisas contemporâneas têm apresentado este exercício sensorial e de disponibilidade em relação às crianças por meio da utilização de diferentes estratégias metodológicas (DELGADO \& MÜLLER, 2005; MÜLLER \& CARVALHO, 2009; FARIA, DERMATINI \& PRADO, 2009; FARIA \& FINCO, 2011; dentre outras). Müller (2007) afirma que os estudos da infância demandam uma abordagem diversificada, articulando observação e outras técnicas de pesquisa. Dentre um leque de possibilidades, o desenho tem potencial de captar a forma expressiva por meio da qual crianças representam o mundo (GOBBI, 1997; 2015; PIRES, 2007).

Pretendemos, com tais reflexões, contribuir para as discussões dos estudos feministas e de gênero ao propor que as desigualdades sociais são construídas a partir das diferenças biológicas percebidas entre os sujeitos (MEAD, 1979; SCOTT, 1995), que, por sua vez, produzem relações assimétricas e hierarquizadas desde a infância. Meyer (2013, p. 20) mostra a necessidade de considerarmos a análise dos processos, estratégias e práticas culturais e sociais que produzem e educam os sujeitos como homens e mulheres de um ou outro tipo, isso para "propor intervenções que permitam modificar, minimamente, as relações de poder de gênero vigentes na sociedade em que vivemos".

Ao analisar desenhos e narrativas de crianças sobre suas representações de família, buscamos abordar práticas desiguais que marcam a educação e o cuidado de meninos e meninas e que são compartilhadas entre a família e a Educação Infantil. Propomo-nos a refletir sobre os processos de subordinação e violência de gênero que ambas instituições ainda mantêm por meio de práticas vivenciadas pelas crianças cotidianamente.

\section{Infância e gênero nas pesquisas}

Estudos clássicos consideraram crianças como somente receptoras da ação dos adultos (MÜLLER, 2010; ABRAMOVICZ \& MORUZZI, 2010; NASCIMENTO et al, 2013). Além de uma "exclusão explícita", Alanen (2001, p. 70) também chama atenção para a "pseudo-exclusão" que tradicionalmente marginalizou a infância como objeto de estudo. A partir de uma visão centrada no adulto, a criança não era compreendida em suas especificidades, mas como um vir-a-ser adulto. Tratava-se de uma concepção teórica e política relacionada ao poder e à manutenção da ordem social que, 
semelhantemente à posição da mulher em sociedades patriarcais, relega a criança a uma posição periférica ou de invisibilidade social (MARCHI, 2011).

A infância contemporânea é produto de uma construção social e histórica do Ocidente. Beck e Guizzo $(2013,180)$, inclusive, sugerem que o termo infâncias seria mais adequado porque trata-se de um período experimentado de forma diferente na vida das crianças e que é recorrentemente inventado e produzido; depende também de outros aspectos, tais como: culturas, sociedades, raças e etnias. Estas mudanças no modo de conceber a criança e a infância foram emergindo simultaneamente com as mudanças na "composição familiar, nas noções de maternidade e paternidade, no cotidiano e na vida das crianças, inclusive por sua institucionalização pela educação escolar" (COHN, 2005, p. 21).

A emergência de um estatuto social próprio das crianças, a saber, a infância, deve ser compreendida a partir de um processo histórico-cultural de construção de representações sobre ela (COHN, 2005). Tal emergência está relacionada ao surgimento do campo da sociologia da infância, que investe a criança de um status próprio e dá visibilidade à sua ação social, construindo uma ciência centrada na criança e descaracterizando-a de sua invisibilidade científica e social. Qvortrup (1993) usa o termo "limbo analítico" ao explicar o recente passado que excluía, no campo científico, a criança do mundo adulto e das relações sociais mais amplas.

Qvortrup (1993) igualmente afirma que a infância é parte da estrutura social, categoria permanente no sentido sociológico, que possui características socioculturais e históricas que se modificam a partir da ação da criança na sociedade e desta para com a criança, em um movimento reflexivo. As crianças, portanto, são co-construtoras da sociedade e da própria infância, por meio de um movimento relacional cujas mudanças refletem em um e em outro.

A criança significa suas experiências interpretando de modo criativo aquilo que está posto e contribui para a transformação da sociedade e a produção de cultura. Contudo, Cohn (2005, p.37) alerta para a "relativa autonomia cultural" das crianças, pois estas compartilham com os adultos um sistema simbólico a partir do qual dão sentido às experiências e constroem suas culturas.

Pensar as relações de gênero implica considerar que as crianças experimentam as mesmas desigualdades sociais as quais os/as adultos/as também estão expostos/as. Logo, as relações sociais pautadas nas diferenças sexuais afetam igualmente a vida das crianças. Isso porque, desde a descoberta da gestação de um bebê já se cria uma expectativa ligada ao sexo da criança: "Talvez não seja exagero afirmar que nossas identidades (de gênero,sexuais, raciais) vão-se delineando, mesmo antes de nascermos, a partir das inúmeras expectativas que são em nós depositadas." (FELIPE \&GUIZZO, 2003, p. 121). Ser menino ou menina em nossa sociedade provoca diferentes formas de ser e viver no mundo, também marcadas por desigualdades, hierarquizações e estereótipos.

Neste sentido, as discussões de gênero e a sociologia da infância evidenciaram a marginalização dos sujeitos e a produção de relações desiguais e hierarquizadas baseadas na imaturidade biológica da criança e na diferença dos órgãos sexuais. Propor uma discussão de gênero e infância exige, portanto, uma desconstrução conceitual e epistemológica, pois diz respeito a categorias sociais tradicionalmente 
invisibilizadas e decorrentes de uma sociedade machista e patriarcal. Assim como as relações de gênero são atravessadas por assimetrias de poder, a infância, enquanto categoria histórico-social, também é marcada por desigualdades relacionadas a outras categorias sociais, tais como: raça, etnia, geração e classe social.

Alanen (2001, p. 73) compara a emergência dos estudos da infância ao princípio dos estudos feministas: tal como a "questão da mulher", as crianças também foram por um longo tempo injustiçadas, "com consequências similares de deixá-las ausentes e de distorcer seu lugar social e suas contribuições". Igualmente, Marchi (2011, p. 399) propõe uma proximidade epistêmica entre a criança e a mulher diante de sua exclusão e silenciamento nas ciências e na sociedade, a partir de uma origem de proximidade física e simbólica no universo social, "caracterizada pela posição de subordinação e dependência do mundo adulto masculino".

Scott (1995) afirma que, historicamente, os estudos de gênero surgiram para descrever a organização social da relação entre os sexos; buscava-se romper com o determinismo biológico e evidenciar os aspectos relacional e assimétrico entre homens e mulheres. $\mathrm{O}$ termo gênero surge mais fortemente em referência aos estudos sobre as mulheres, o que demandou um reposicionamento epistêmico para incluir a fala de oprimidas e a análise de sua posição inferiorizada, considerando que as desigualdades estão ancoradas, no mínimo, sobre as categorias gênero, raça e classe.

Contudo, ainda que pesquisadoras buscassem inserir as discussões e elevá-las ao nível de compreensão dos fenômenos sociais, as abordagens utilizadas se limitavam à mera descrição ou à formulação de teorias para explicar as razões pelas quais acontecem daquela forma. Partindo deste contexto, Scott (1995) propõe a utilização de gênero enquanto categoria de análise, concebendo-a enquanto forma primária de significar as relações sociais e de poder baseadas nas diferenças percebidas entre os sexos. Assim, gênero passa a englobar os processos sociais de construção e manutenção das relações assimétricas entre os sujeitos por meio de: 1) símbolos culturalmente disponíveis que evocam representações múltiplas; 2) conceitos normativos expressos em doutrinas religiosas, educativas, jurídicas, científicas e políticas; 3) instituições e organizações sociais; e 4) constituição da identidade subjetiva por meio do controle ou acesso diferencial aos recursos materiais e simbólicos.

A partir destes elementos que não ocorrem de forma isolada, mas relacionam-se entre si, é possível refletir acerca dos processos que marcam a infância das crianças e os processos de subordinação e desigualdade vivenciados por elas no contexto familiar e da Educação Infantil. Ademais, como argumenta Alanen (2001, p. 73, grifos da autora), "gênero é essencialmente um conceito de relação - mas infância também o é".

\section{Crise do patriarcado e as transformações nas famílias}

Na Introdução de "Rethinking the Family", ainda no início dos anos de 1990, Thorne (1992, p. 45) sintetizou cinco pontos que, para além de diferenças teóricas das autoras dos capítulos que se seguiam 
na obra, são centrais para o feminismo, na sua redefinição de família. Estes cinco pontos são: 1) foram as feministas que criticaram a noção de marido trabalhador e mulher dona-de-casa como um arranjo natural, biológico ou funcional imutável; 2) a teoria da família recebeu contribuições ao incorporar gênero como uma categoria de análise, assim como outras formas de desigualdade; 3) ao criticarem a exaltação da família nuclear, foi possível compreender que estruturas de gênero, geração, raça e classe social impactam na diversidade da vida familiar; 4) as feministas sugeriram conexões entre a vida familiar e o mundo do trabalho, o estado de bem-estar social, o sistema legal, a escola e a Educação Infantil; e 5) as noções de público e privado tem a ver com uma histórica dicotomia entre os valores do individualismo (geralmente negado às mulheres) e comunidade (associada aos valores femininos), cuja tensão é fundamental para a transformação de políticas de mudança da família. Ou seja, a produção teórica e a militância das feministas permitiram ampliar e aprofundar as visões sobre os múltiplos papéis das mulheres na família e no mundo social mais amplo. Associado a isto, transformações sociais, políticas, econômicas e culturais influenciaram decisivamente a definição de família. Os valores patriarcais delimitaram a função social de cada sujeito e a distribuição de poder entre seus membros. A base das relações era a consanguinidade que definia quem pertencia ou não à família.

O patriarcalismo encontra na família a sua principal forma de legitimação por meio de relações intrafamiliares nas quais o homem desfruta de maior poder e direitos, enquanto a mulher possui mais obrigações e menos direitos (THERBORN, 2006). Corroborando o argumento, Castells (1999, p.169, grifos do autor) afirma: "Não fosse a família patriarcal, o patriarcalismo ficaria exposto como dominação pura e acabaria esmagado pela revolta da 'outra metade do paraíso', historicamente mantida em submissão".

Castells (1999) e Therborn (2006) concluem que as transformações decisivas para a mudança e a reorganização familiar dizem respeito, principalmente, ao empoderamento das mulheres. Isto colaborou para o declínio das formas tradicionais de família e dos valores patriarcais. Castells (1999) apresenta os fatores que têm contribuído para o fim do patriarcalismo, sendo um deles, a transformação na economia e no mercado de trabalho que possibilitou à mulher sair do mundo privado rumo a vida pública. Homem e mulher provém juntos o sustento da família, exigindo uma renegociação no contrato da família heterossexual na distribuição do trabalho doméstico e do cuidado e educação dos/as filhos/as (THERBORN, 2006).

Outro fator diz respeito às transformações tecnológicas ocorridas na medicina, na biologia e na farmacologia. Tais transformações possibilitaram à mulher maior domínio sobre o seu corpo e a intervenção na reprodução humana, quebrando o caráter natural atribuído à procriação (SARTI, 2007).

Destacamos ainda um importante propulsor para a crise no patriarcado, qual seja, o desenvolvimento dos movimentos feministas e a rápida difusão de ideias em uma cultura globalizada. Ambos possibilitaram o questionamento das atribuições assimétricas entre mulheres e homens, dos relacionamentos abusivos de dominação e de subordinação e das desigualdades de gênero expressas em instituições, práticas cotidianas e nos relacionamentos sociais. 
A literatura mostra a tendência declinante do modelo de família nuclear de bases patriarcais (BERQUÓ, 1998; OLIVEIRA, et al, 2012; GIBIM, 2017), ao mesmo tempo em que evidencia algumas permanências no que diz respeito, por exemplo, à relação determinista de obrigatoriedade da mulher pela educação e cuidado de crianças pequenas. Igualmente, estudos contemporâneos (FONSECA, 2002; 2005; SARTI, 2004; 2007;) sugerem o declínio dos modelos analíticos tradicionais sobre a família heteronormativa ${ }^{4}$ e nuclear. Neste sentido, a crise do modelo hegemônico de família é evidenciada diante da diversidade de dinâmicas familiares próprias e não passíveis de conceitos generalizadores.

De acordo com Gibim e Finco (2016, p. 118), representações políticas e sociais embasaram uma noção de família que permaneceu no imaginário social como ideal coletivo, impondo-se como norma a toda população:

Por muito tempo a ideia de família esteve atrelada à sua constituição nuclear tradicional com pai, mãe e filho(a). Trata-se de um conceito heteronormativo e patriarcal, que concebe um único modelo familiar como ideal. Por meio de símbolos culturalmente disponíveis que evocam representações múltiplas; conceitos normativos expressos em doutrinas científicas, educativas, políticas ou jurídicas; noções políticas referents às organizações e instituições sociais que determinam aos sujeitos formas de se relacionarem e de se organizarem socialmente; e processos de formação da identidade subjetiva dos sujeitos que expressam formas distintas de controle e poder sobre estes (Scott, 1995) é que tal instituição foi sendo mantida e consolidada.

Assim, para compreender mudanças nas famílias, é preciso considerar gênero e geração, uma vez que ambas as categorias estão presentes na constituição das relações familiares e que se baseiam no patriarcado (GIBIM, 2017). O conceito de família, portanto, não pode mais ser compreendido a partir de postulados tradicionais e biológicos, mas em sua multiplicidade de significações atribuídas pelos sujeitos às experiências vividas. Sarti (2004) afirma que a família é um filtro através do qual se vê e significa o mundo. Trata-se de um universo de relações que se delimita simbolicamente por meio de elos morais que permitem aos sujeitos construírem suas identidades.

Fonseca (2005) mostra que familias têm dinâmicas próprias, construídas a partir de uma rede de parentescos para além do consanguíneo com características espaciais. Vidas que se cruzam e que se unem por meio de relações simbólicas, de afeto ou de elos morais e que transcendem a ideia de família como sistema de reprodução biológica (GIBIM, 2017).

\section{Relações intrafamiliares sob a ótica da criança}

As crianças são sujeitos criativos, produtores de cultura e agentes da história (MÜLLER \& CARVALHO, 2009; ABRAMOVICZ \& MORUZZI, 2010; FARIA \& FINCO, 2011; NASCIMENTO et al, 2013). Estão imersas em um mundo em constante transformação que influencia suas vidas e do qual participam. Crianças constroem representações sobre pessoas, objetos e fenômenos, sejam eles próximos

\footnotetext{
${ }^{4}$ Vianna e Ramires (2008) escrevem sobre a ausência de visibilidade da diversidade sexual nas discussões sobre família, que podem expressar relações de poder que sustentam um modelo ainda patriarcal.
} 
ou distantes geograficamente a elas. Tais representações orientam sua maneira de ser, agir e intervir no mundo, no modo como se colocam diante do outro e nas relações que constroem.

As representações de família estão atreladas, muitas vezes, à construção social de um ideal baseado no patriarcado. Contudo, as demandas políticas, econômicas e sociais afetam a concepção de família que, diante de abalos internos e externos, tem o seu caráter natural reconstruído. A família se desvincula de um processo meramente biológico e natural para ser concebida como processo simbólico e afetivo (OLIVEIRA, 1999), relacionado a elos morais construídos entre seus membros (SARTI, 2004).

Em estudo realizado com crianças de cinco anos, usuárias de Educação Infantil, sobre a temática famílias, relações intergeracionais e de gênero, Gibim (2017) demonstrou que as crianças apresentam configurações familiares distintas a um modelo hegemônico. O estudo buscou captar as representações de crianças, mães e avós sobre os processos de compartilhamento de cuidado e educação com a instituição de Educação Infantil. A partir de desenhos e narrativas com as crianças e entrevistas com as avós e as mães, a pesquisa analisou representações de família e funções sociais ligadas a cada um de seus membros, bem como a forma como estas têm sido acolhidas pela Educação Infantil. O estudo demonstrou permanências e transformações ligadas à família e à função social da mulher na parceria com a Educação Infantil.

No presente artigo apresentaremos um novo tratamento aos desenhos e às narrativas das crianças. O desenho não é um recorte da realidade, mas uma representação do social informado por um tempo histórico e cultural do qual a criança participa (GOBBI, 2014). Segundo Gobbi (2014, p. 155), "é um fragmento bom para pensar sobre diferentes questões teóricas e práticas referentes às dinâmicas sociais, envolvendo ou não as crianças, mas que podem seguramente partir delas".

Os dois desenhos subsequentes foram realizados por Khallel e Pablo e tinham como tema a família. A leitura do "Livro da família" (PARR, 2003) catalisou uma conversa sobre a família das crianças. $\mathrm{Na}$ sequência, foi proposto que fizessem um desenho sobre a temática e, durante a sua realização, Gibim (2017) registrou diversas narrativas das crianças. Khallel desenhou uma família extensa que incorporou 11 pessoas e dois animais, quais sejam: mãe, pai, irmã casada e que mora em outra casa, Tio Marcos, Tio Carlos, Tia Paula, Prima Lorena, Primo Felipe, Giovana, Tia Dete, Tia Rê, Prima Sophia, um outro tio, Carlos, minha tia, tartaruga, cachorro. Interessante notar que Khallel associa um pronome possessivo quando trata dos parentes, mas ao tratar do cachorro faz questão de demarcar a posse do pai. Isto é, mesmo que os animais pertençam à família, como coletivo, também há uma demarcação interna do individual.

Embora coabite somente com a mãe e o pai, a sua ideia de família está relacionada às pessoas e aos animais com quem possui laços afetivos. Há uma divisão, no entanto, marcada no desenho: Khallel, sua mãe e seu pai, assim como os animais de estimação, encontram-se em primeiro plano e inclusive proporcionalmente maiores do que os outros oito membros da família, posicionados em segundo plano e evidentemente menores. Isto pode ser interpretado como uma escala afetiva, que coincide com a unidade doméstica, mas não se resume a ela. Um elemento interessante da ação das pessoas representadas neste desenho é que se encontram, na sua maioria, de braços abertos. A presença de outras pessoas, para além 
da constituição nuclear, é explicada por Khallel tendo em vista o compartilhamento da responsabilidade e cuidados entre os membros das famílias, principalmente entre as mulheres (FONSECA, 2006).

Figura 1: Desenho de Khallel

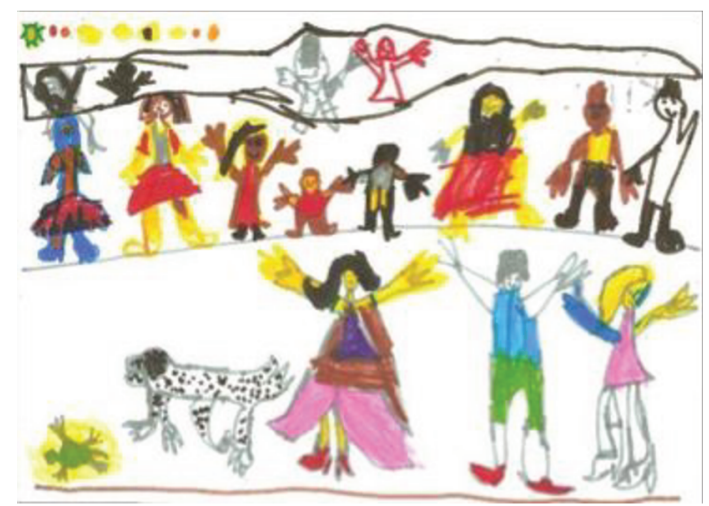

Fonte: Gibim (2017)
Figura 2: Desenho de Pablo

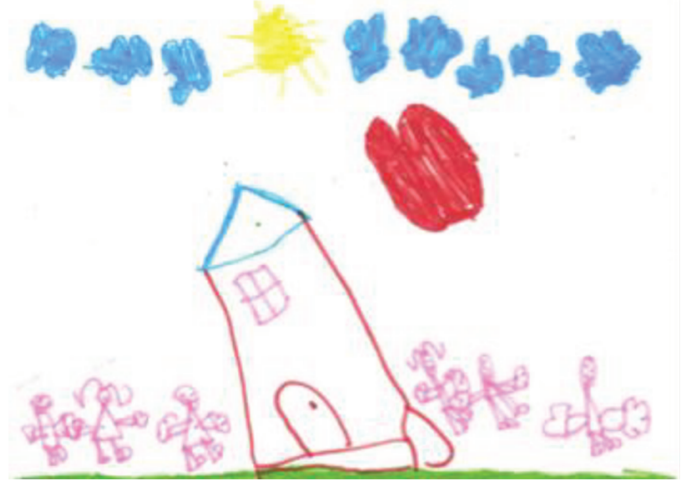

Fonte: Gibim (2017)

Já o desenho de Pablo conta com seis pessoas - "Meu irmão (11 anos), minha irmã (7 anos), meu irmão (9 anos), minha vó (57 anos), minha mãe e meu pai" -, que coabitam a mesma unidade doméstica que Pablo. O desenho conta com elementos interessantes, como a casa onde a família mora, assim como um grande coração, que, sem dúvida, é um símbolo de afeto em nossa cultura. O pai não é biológico, mas é assim nomeado por Pablo devido aos laços de afeto. Pablo inclui a avó na rotina diária da família; sua participação é efetiva na divisão do trabalho doméstico e do cuidado com as crianças com a sua mãe, assim como também nos momentos de brincadeira. Pablo conta que sua avó ensina, dá conselhos, brinca e cuida dele.

A avó, antiga e nova figura das famílias, surge como mantenedora, segunda mãe ou matriarca da família (GIBIM, 2017). Por meio de experiências cotidianas, há um processo de coeducação geracional entre velhos e novos que possibilita a transformação identitária de ambos por meio de vidas compartilhadas (OLIVEIRA, 1999). Neste contexto, trata-se de uma figura que dá suporte à filha e que, por muitas vezes, estende seu papel de mãe para os/as netos/as, atualizando-o a partir de experiências de vida, autorreflexão e transformação identitária (GIBIM, 2017).

Embora a participação da mulher no mercado de trabalho seja efetiva, valores patriarcais presentes na sociedade atribuem a ela demasiadas responsabilidades, exigindo a conciliação das "quádruplas jornadas diárias - trabalho remunerado, organização do lar, criação dos filhos e jornada noturna em benefício do marido" (CASTELLS, 1999, p. 170). Isso demanda o compartilhamento das funções de maternagem com outras mulheres, neste caso, a avó.

Os laços de consanguinidade também não são determinantes para a organização das famílias e para a negociação das responsabilidades diante das crianças (SARTI, 2007; FONSECA, 2005). Por meio do estabelecimento de laços simbólicos e afetivos, as famílias se constituem com dinâmicas próprias, já que "As atividades do dia-a-dia envolvem uma rede que se estende no espaço para outras casas e até 
mesmo para outros bairros. Traçando as linhas de ajuda mútua, podemos melhor refletir sobre o que é, nessa instância, a família pertinente" (FONSECA, 2005, p. 53).

Os desenhos subsequentes, de Livia e de Isabela, foram realizados a partir do tema "avó". A proposta do desenho foi catalisada pelo "Livro da vovó" (PARR, 2010), seguida de uma conversa acerca das avós das crianças. Após ambas as atividades, foi proposto que as crianças realizassem um desenho.

Livia desenhou a si própria, assim como duas irmãs, uma menor e uma da mesma idade (gêmea), na casa da avó. Ela disse que gosta que sua avó cozinhe para ela. Livia contou que sua casa fica próxima a de sua avó, mas que ela costuma ir lá somente aos sábados e domingos. A presença da avó, de vestido cor-derosa, na cozinha, onde prepara a comida em frente a um fogão, também cor-de-rosa, expõe alguns estereótipos de gênero que as crianças preservam em seus desenhos.

A predominância de uma cor associada ao feminino ou ao masculino e que permeia os desenhos das crianças pequenas tem a ver com experiências das quais elas participam enquanto meninas ou meninos. Segundo Gibim, Pimenta e Silva (2015), estas cores estão presentes em outros artefatos culturais, tais como: brinquedos, roupas, mochilas, cadernos, que acabam por reforçar os estereótipos de gênero na infância. Pimenta (2016) trata a imposição das cores rosa e azul como escolhas dos adultos para as crianças e formas de colonização da infância.

Figura 3: Desenho de Livia

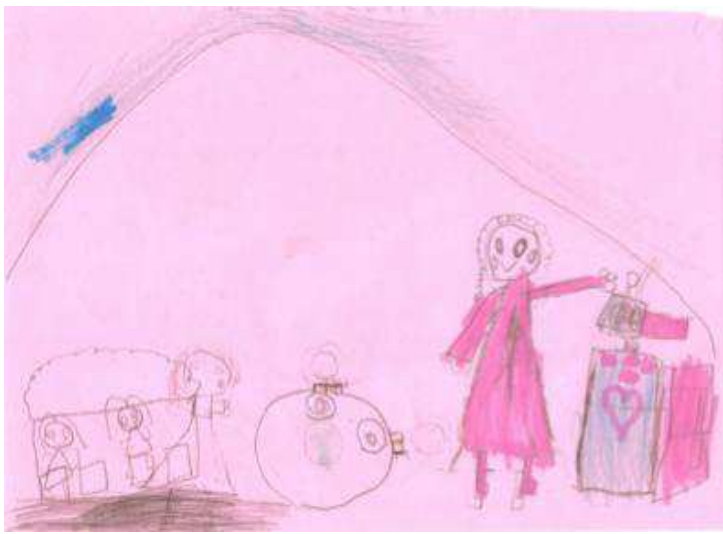

Fonte: Gibim (2017)
Figura 4: Desenho de Isabela

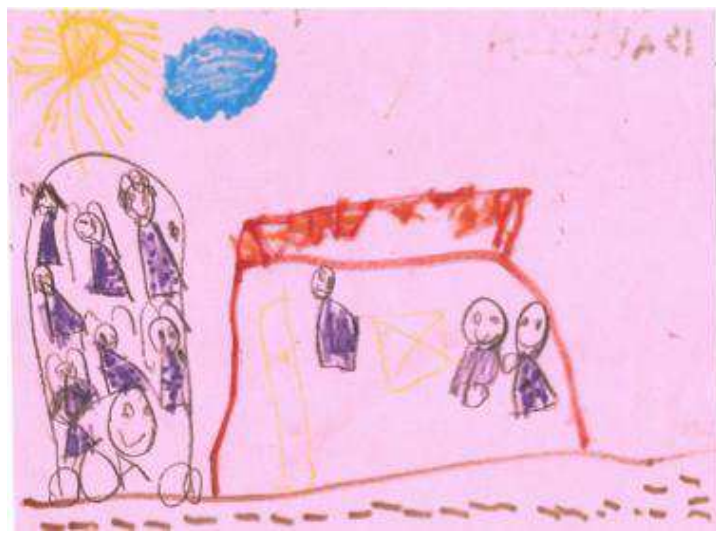

Fonte: Gibim (2017)

Isabela desenhou a si própria; o tio de sete anos, filho de sua avó; a avó na casa desta última; os demais membros da família foram desenhados no carro do pai. Segundo Isabela, ela costuma ir com frequência à casa da avó depois da escola, onde encontra o tio, enquanto sua mãe e seu pai ficam na "vila" (local onde fica a casa de Isabela). A proximidade das casas permite que a avó participe com frequência da rotina de Isabela; segundo a menina, ela vive "enchendo o saco" da avó, uma reprodução do que escuta de seu pai. O desenho ainda mostra que Isabela e seu tio estão em uma situação de interação, enquanto a avó encontra-se em outro espaço da casa. Neste contexto, ainda que a avó disponha de mais tempo com as crianças pelo fato de não trabalhar fora, suas atribuições como mulher não possibilitam muitos momentos lúdicos com a neta e o filho. Ao narrar os momentos que passam juntas, Isabela disse que sua vó cozinha, 
cuida dela, lava o quintal, mas não comenta sobre brincadeiras como parte da relação no âmbito doméstico. Todavia, quando a avó precisa sair e levar consigo Isabela e o tio, isto é entendido por Isabela como "passear"

A presença das avós nestas famílias é observada no compartilhamento do cuidado e da educação das crianças, o que demonstra uma forte associação da maternagem ao feminino e à mulher (CERISARA, 1998; ROSEMBERG, 2015), legitimado por meio da participação das crianças nas relações familiares.

Os desenhos de Sophia e de Gustavo (Figuras 5 e 6) tratam do tema "mãe". Primeiramente foi feita a leitura do "Livro da mamãe" (PARR, 2007), seguida de uma conversa e desenho. Particularmente com relação ao tema "mãe", é interessante que o livro introduz diversos contextos de participação da mulher na sociedade, superando alguns estereótipos de mulher ligada à maternagem e à unidade doméstica.

Contudo, as crianças associaram a mãe às funções de cuidado e à imagem da casa. Além disso, ainda que as crianças vivenciem com as mães práticas não só ligadas ao cuidado, esta característica é marcante e recorrente nos desenhos analisados. Isso pode ser explicado a partir da lógica patriarcal. Segundo Pimenta (2016, p.107), os desenhos de meninas e de meninos carregam mensagens de gênero que separam trabalho e lazer, "com base nas relações de poder, controle e força", semelhantemente ao preconizado pelas sociedades patriarcais.

Sophia desenhou sua mãe "na casa da vizinha olhando os bebês". De acordo com Sophia, a vizinha também a cuida quando sua mãe está trabalhando. Esse tipo de relação evidencia as trocas recíprocas entre mulheres diante das demandas econômicas e sociais que as assolam. Cria-se uma rede de apoio como forma de socialização e de divisão de responsabilidades entre as mulheres que garante a conciliação das diversas jornadas de trabalho.

Figura 5: Desenho de Sophia

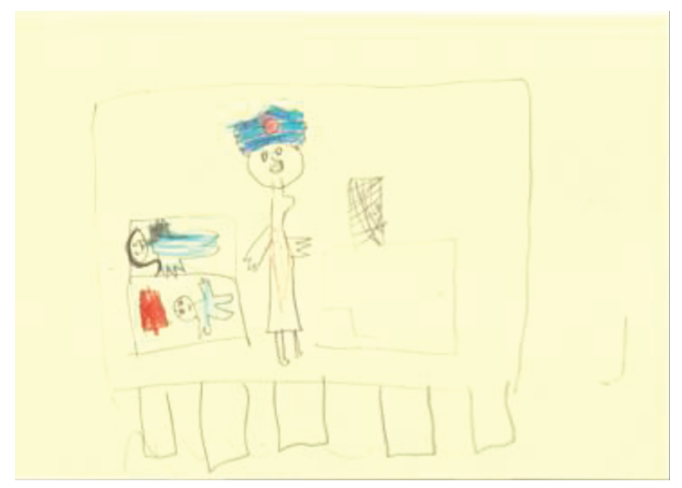

Fonte: Gibim (2017)
Figura 6: Desenho de Gustavo

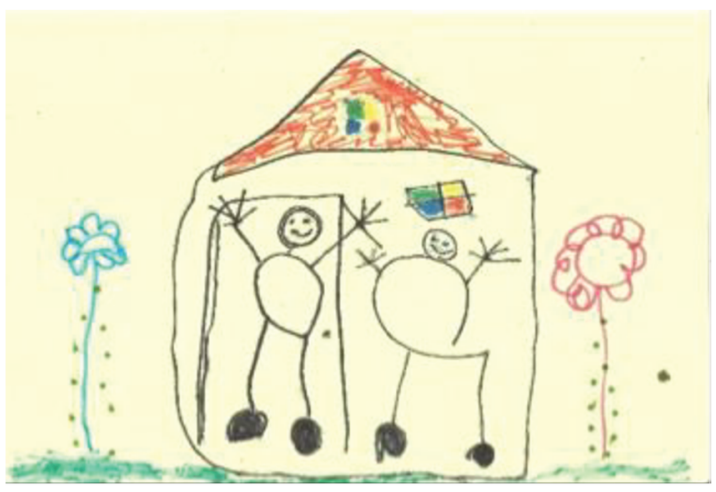

Fonte: Gibim (2017)

Diferentemente de Sophia, Gustavo não desenhou o interior da casa, mas sua narrativa dá ênfase aos sujeitos do desenho. Gustavo desenhou a si próprio e sua mãe; disse que ela estava em casa cozinhando arroz. Foi perguntado sobre o pai, ao que respondeu que ele estava assistindo televisão. No desenho, há duas flores: uma rosa ao lado da mãe e outra azul ao lado dele. Estes elementos são 
interessantes para pensar algumas construções de gênero abordadas pelas crianças. Primeiramente, as cores associadas às pessoas têm a ver com uma construção social da qual as crianças participam desde tenra idade e que é nomeada por Gibim, Pimenta e Silva (2015) de "ditadura das cores". Trata-se de um importante aspecto da cultura da infância, "poderosa mensagem simbólica de gênero, na qual é possível fazer uma leitura de como as hierarquias de uma cultura são inscritas e presentes nos desenhos das crianças e de como também são desconstruídas" (PIMENTA \& SILVA, 2015, p. 237).

Com relação à função social da mulher na família, ao desenharem suas mães e avós, as crianças as associaram ao cuidado e educação na família e no âmbito doméstico. Ao realizar uma investigação sobre as relações de gênero no desenho de meninas e de meninos na Educação Infantil, Pimenta (2016) constatou que crianças apresentam a maternagem e o trabalho doméstico ligados quase que exclusivamente ao universo feminino, por meio de um processo de imitação e de apropriação das representações sociais de poder, submissão e práticas generificadas.

As crianças apresentaram diferentes marcas produzidas por estereótipos ligados ao feminino e ao masculino e que permeiam as relações sociais. Aos homens da casa foram associadas atividades de trabalho externo ao contexto doméstico, tais como: dirigir um carro e usufruir de momentos lúdicos com as crianças. Já às mães e avós foram descritas atividades relacionadas ao cuidado.

Goellner (2013) enfatiza a necessidade de romper com a naturalização dos corpos e considerar os processos educativos que produzem sujeitos sociais. Tais processos são atravessados por representações decorrentes de valores que embasam a sociedade em suas diversas instâncias e instituições, inclusive as famílias. Neste sentido, os significados culturais e sociais atribuídos a estes corpos é que irão defini-los. As mulheres narradas pelas crianças são caracterizadas como um ideal, mãe que cuida dos filhos e da casa. Tais representações são reflexos de um contexto social, histórico e econômico que define, essencialmente, um tipo de mulher e de feminilidade e que anula outras possibilidades por meio de um mecanismo perverso de imposição social.

Badinter (1985) questiona as construções sociais em torno do ser mulher e problematiza as relações maternais produzidas socialmente ao denunciar o mito do amor materno. Atrelada a esta discussão, Badinter (2011) ainda sugere a desnaturalização da maternidade, provocando-nos a pensar sobre as implicações de ser mulher na sociedade contemporânea. Embora ser mãe não seja a única identidade possível, há um apelo social que evoca a representação de mãe ideal como parte da constituição feminina. Badinter (2011) utiliza o termo "tirania dos deveres maternos" para explicar as cobranças sociais impostas às mulheres. Ainda que nas sociedades patriarcais a maternagem seja uma atribuição ligada exclusivamente à mulher (CERISARA, 2008), trata-se de uma função que pode ser atribuída a qualquer pessoa, independente do sexo.

As crianças participantes da pesquisa de Gibim (2017) encontravam-se no último estágio da Educação Infantil e já tinham ingressado na creche desde bebês. Neste sentido, a pesquisa mostra o quanto é preciso problematizar as relações de gênero e incluir estas discussões na formação continuada de professoras, visto que muito daquilo que as crianças apresentam tem a ver com um processo de 
socialização que naturaliza construções sociais em torno do ser mulher ou homem. Esta observação é evidente nos desenhos e nas narrativas, que comunicaram como as crianças estão construindo identidades de gênero.

Os dados de Gibim (2017) também apresentam uma concepção binária e patriarcal de gênero presente nos espaços e tempos da Educação Infantil: fila de meninos e fila de meninas; chamada que separa meninos de meninas; cantinhos de brincadeiras com panelas em miniatura e bonecas para meninas, e carrinho para meninos; jogos e brincadeiras competitivas organizadas em equipes de meninos contra equipe de meninas; entre outras situações que reforçam a distinção das oportunidades dadas de acordo com o gênero.

É preciso considerar que as crianças não são passivas neste processo. Por meio de sua participação e papel ativo na sociedade, elas reelaboram suas experiências significando-as de modo diferente da lógica adulta. Sua capacidade plástica de aprender, construir e reelaborar as experiências possibilita a transformação constante de suas identidades, deixando margem para que nós, adultos/adultas, criemos situações planejadas no contexto da Educação Infantil que proporcionem relações mais igualitárias, não sexistas e livres de estereótipos.

\section{Considerações finais}

Ao atentarmos para as marcas de gênero que atravessam os relacionamentos intrafamiliares, é possível perceber que muitos estereótipos devem ser desconstruídos. Meninas e meninos vivenciam diariamente práticas desiguais decorrentes de concepções marcadas pela diferença nos órgãos sexuais. Oportunidades e barreiras podem ser observadas à medida em que as crianças frequentam diferentes contextos sociais durante o seu desenvolvimento. Estes contextos, erigidos em bases patriarcais, refletem lutas e conflitos que perpassam a sociedade. O contexto sociopolítico brasileiro atual, por exemplo, é reflexo destas raízes que insistem em permanecer e que se materializam em uma onda conservadora que defende a família tradicional e seus valores patriarcais (GIBIM, 2017). As discussões acerca das desigualdades de gênero têm sido silenciadas em prol de uma ideia de família e sociedade arcaicas gestadas no século XVI. Como afirma Therborn (2006, p.195):

A despeito das tremendas e marcantes mudanças, é pesada a carga de dominação paterna e marital trazida para o século XXI. A longa noite patriarcal da humanidade está chegando ao fim. Está alvorecendo, mas o sol é visível apenas para uma minoria.

Ao considerar desenhos e narrativas das crianças como técnicas de pesquisa, foi possível não só captar aquilo que elas apresentam enquanto apreensão do social, mas também as representações e significados atribuídos às experiências de gênero que vivenciam na sociedade e na família. Por meio do desenho foi possível compreender a riqueza de detalhes nos processos comunicativos de crianças, além de permitir a elas uma situação menos assimétrica em relação ao adulto.

Os desenhos mostraram algumas permanências com relação às experiências de gênero, dando ênfase a papéis e experiências desiguais entre homens e mulheres. Contudo, as crianças também atualizam 
e interpretam estas experiências de gênero, transgredindo a lógica patriarcal. Todavia, tais análises não foram abordadas neste artigo e são mais bem discutidas em Gibim (2017) e Pimenta (2016).

A Educação Infantil é um contexto de compartilhamento de cuidados e educação da primeira infância com as famílias. É por meio do contato com diferentes crianças e adultos que papéis sociais podem ser transformados, promovendo processos de mudanças identitárias individuais e na família. Por isso, as discussões apresentadas neste artigo sugerem a necessidade de conceber a criança, sua cultura e sua história como centrais no processo educacional.

A instituição de Educação Infantil pode ajudar a desconstruir qualquer forma de naturalização das relações sociais de parentesco, evidenciando e legitimando diversas possibilidades de educação e de cuidado das crianças, ou seja, "a produção política sobre o que é 'natural' nas relações familiares é um processo atualizado a cada novo dia." (FONSECA, 2009, p. 71, grifo da autora). Pode transformar suas práticas para acolher as diferentes configurações familiares e partilhar a construção de práticas que possibilitem às crianças viverem suas infâncias livres de preconceitos e desigualdades de gênero. Incluir a discussão sobre a função social da mulher na sociedade é essencial para garantir a progressiva responsabilização social pela criança, independente do gênero ou sexo, e estabelecer um diálogo livre de estereótipos de gênero.

$\mathrm{Na}$ história da luta pelo atendimento aos bebês e crianças, o movimento feminista concebia as instituições de Educação Infantil como desdobramento do direito das mulheres ao trabalho e à participação política. O movimento criticou o papel tradicional da mulher na família e defendeu a responsabilidade de toda a sociedade em relação à educação das novas gerações. "O filho não é só da mãe" informavam os cartazes nas manifestações (ROSEMBERG, 1989).

Ainda que as pressões sociais busquem o reconhecimento da partilha e negociação das responsabilidades sobre as crianças, pesquisas como a de Rosemberg (2015) demonstram que ainda há muito a ser conquistado. Políticas que visem o bem-estar da criança e da família precisam ser consolidadas e discutidas à luz dos estudos feministas, que denunciam a desigual carga de responsabilidade atribuída a homens e mulheres com relação às crianças.

O movimento feminista inclui na sua bandeira de lutas o questionamento a toda e qualquer forma de opressão e de dominação. A articulação da luta feminista às discussões sobre gênero e infância pode denunciar relações de poder desiguais que marcam a educação e o cuidado de meninas e meninos. $\mathrm{O}$ empoderamento sobre suas vidas se inicia na pequena infância, por meio de experiências político-sociais que promovam o conhecimento de si e do outro em um contexto não sexista, machista ou homofóbico, ou seja,onde seja possível crescer e participar das mesmas oportunidades independentemente de classe social, gênero, geração ou raça/etnia. 


\section{Referências}

ABRAMOWICZ, A.; MORUZZI, A. B. O plural da Infância: aportes da sociologia. 1ª Ed. São Carlos: EDUFSCar, 2010.

ALANEN, L. Estudos feministas/Estudos da infância: paralelos, ligações e perspectivas. In.: RABELLO DE CASTRO, L. Crianças e jovens na construção da cultura. Rio de Janeiro: NAU Editora, 2001. p. 69-92.

BADINTER, E. O conflito: mulher e mãe. Rio de Janeiro: Record, 2011.

Um amor conquistado: o mito do amor materno. Rio de Janeiro: Nova Fronteira, 1985.

BECK, D. Q; GUIZZO, B. S. Estudos culturais e estudos de gênero: proposições e entrelaces às pesquisas educacionais. Holos, v. 4, p. 172-182, set. 2013. Disponível em: https://doi.org/10.15628/holos.2013.1597 Acesso em: 06.11.2017.

BERQUÓ, E. Arranjos familiares no Brasil: Uma visão demográfica. In: SCHWARCS, L. M. (Org.). História da vida privada no Brasil: contrastes da intimidade contemporânea, vol. 4, São Paulo: Companhia das letras, 1998, p. 411-437.

CASTELLS, M. O fim do patriarcalismo: movimentos sociais, família e sexualidade na era da informação. In.: A era da informação: economia, sociedade e cultura, vol.2 - O poder da identidade. São Paulo: Paz e Terra, 1999. p. 69-285.

CERISARA, A. B. Educadoras de Creche: Entre o Feminino e o Profissional. Seminário de Pesquisa em Educação da Região Sul, 1998, Florianópolis. CD Rom do Seminário de Pesquisa em Educação da Região Sul. Florianópolis, 1998.

COHN, C. Antropologia da criança. Rio de Janeiro: Ed. Jorge Zahar, 2a Ed., 2005.

CORSARO, William A. Sociologia da infância. Porto Alegre: Artmed, 2011.

CRUZ, S. H. V. (Org.). A criança fala: a escuta da criança em pesquisas. São Paulo: Cortez, 2008.

DELGADO, A. C. C.; MÜLLER, F. Apresentação. Educação \& Sociedade, Campinas, v. 26, n. 91, p. 351-360, ago. 2005. Disponível em: http://dx.doi.org/10.1590/S0101-73302005000200002 Acesso em: 25.11.2017.

FARIA, A. L. G.; FINCO, D. (Orgs.). Sociologia da Infância no Brasil. Campinas: Autores Associados, 2011.

FARIA, A. L. G.; DEMARTINI, Z. B. F.; PRADO, P. D. (Orgs.). Por uma cultura da infância: metodologias de pesquisa com crianças, Campinas: Autores Associados, 2009. 
FELIPE, J; GUIZZO, B. S. Erotização dos corpos infantis na sociedade de consume. Pro-Posições, v. 14, n. 3 (42), p. 119-130, set./dez. 2003. Disponível em: https://periodicos.sbu.unicamp.br/ojs/index.php/proposic/article/view/8643865/11342 Acesso em: 14.11.2017.

FINCO, D. Gênero, infância e cidadania: desafios para a formação docente na Educação infantil. In: XII CONLAB - Congresso da Associação Internacional de Ciências Sociais e Humanas em Língua Portuguesa: Imaginar e Repensar o Social: Desafios às Ciências Sociais em Língua Portuguesa, 25 anos depois, 2015, Lisboa, v. 1. p. 1-9.

Educação Infantil, espaço de confrontos e convívio com as diferenças: análise das interações entre professoras e meninas e meninos que transgridem as fronteiras de gênero. 216f, 2010. Tese (Doutorado) - Faculdade de Educação da Universidade de São Paulo, programa de pós-graduação em Educação, 2010.

FONSECA, C. Olhares antropológicos sobre a família contemporânea. Participação na Mesa Redonda: O lugar da família na ciência contemporânea: desafios e tendências na pesquisa. Congresso Internacional Pesquisando a Família, Florianópolis 24-26 de abril, 2002.

Concepções de família e práticas de intervenção: uma contribuição antropológica. Saúde e Sociedade. v.14, n.2, p.50-59, maio-ago 2005. Disponível em: http://dx.doi.org/10.1590/S0104$\underline{12902005000200006}$ Acesso em: 22.09.2017.

Da circulação de crianças à adoção internacional: questões de pertencimento e posse. Cadernos Pagu, v. 26, p.11-43, jan.-jun 2006. Disponível em: http://dx.doi.org/10.1590/S010483332006000100002Acesso em: 04.10.2017.

FORTUNATI, A.A educação infantil como projeto da comunidade: crianças, educadores e pais nos novos serviços para a infância e a família: A experiência em San Miniato. Porto Alegre: Artmed, 2006.

FREYRE, G. Casa grande e senzala. 51ª Ed. São Paulo: Global Editora, 2006.

GIBIM, A. P. P. G.; FINCO, D. Relações de gênero e processos de despatriarcalização das famílias sob a ótica das crianças. REVISTA NEP (Núcleo de Estudos Paranaenses), Curitiba, v.2, n.5, p. 115-131, dez. 2016. Disponível em: http://dx.doi.org/10.5380/nep.v2i5.49564Acesso em: 18.09.2017.

GIBIM, A. P. P. G.Famílias, relações intergeracionais e de gênero: práticas compartilhadas no cuidado e educação na Educação Infantil. Dissertação (Mestrado em Educação). Escola de Filosofia, Letras e Ciências Humanas, Universidade Federal de São Paulo, Guarulhos, 2017. 
GIBIM, A. P. P. G.; PIMENTA, D. D.; SILVA, T. J. Diferenças Culturais e a educação da pequena infância: descolonizando os olhares nas pesquisas com meninas e meninos. Anais do II Seminário infâncias e pós-colonialismo: pesquisas em busca de pedagogias descolonizadoras. Campinas, p. 233$248,2015$.

GOBBI, M. A. Lápis vermelho é de mulherzinha: desenho infantil, relações de gênero e educação infantil. Dissertação (Mestrado em Educação) - Faculdade de Educação, Universidade Estadual de Campinas, Campinas, 1997.

Lápis vermelho é de mulherzinha. Vinte aos depois... In: FINCO, D.; GOBBI, M. A.; FARIA,

A. L. G. Creche e feminismo. Campinas: Edições Leituras Críticas, 2015. p. 137-161.

GOBBI, M. A.; Pinazza, M. A. (Orgs.). Infância e suas linguagens. $2^{a}$ Ed. São Paulo: Cortez Editora, 2017.

GOBBI, M. A. Mundos na ponta do lápis: desenhos de crianças pequenas ou de como estranhar o familiar quando o assunto é criação. Linhas Críticas, Brasília, DF, n. 41, jan./abr. 2014, p. 147-165. Disponível em: http://periodicos.unb.br/index.php/linhascriticas/article/view/12425/8646 Acesso em: 28.10.2017.

GOELLNER, S. V. A produção cultural do corpo. In: LOURO, G. L; FELIPE, J.; GOELNNER, S. V. (Orgs.). Corpo, gênero e sexualidade: um debate contemporâneo na educação, $9^{a}$ Ed. Rio de Janeiro: Vozes, 2013. p. 30-42.

MAYALL, B. Relações geracionais na família. In: MÜLLER, F. (Org.). Infância em Perspectiva: políticas, pesquisas e instituições. São Paulo: Cortez, 2010, p. 165-186.

MEAD, M. Sexo e Temperamento. $2^{a}$. ed. São Paulo: Perspectiva, 1979

MEYER, D. E. Gênero e educação: teoria e política. In: LOURO, G. L.; FELIPE, J.; GOELNNER, S. V. (Orgs.). Corpo, gênero e sexualidade: um debate contemporâneo na educação, $9^{a}$ Ed. Rio de Janeiro: Vozes, 2013. p. 11-29.

MÜLLER, F.; CARVALHO, A. M. A. (Orgs.) . Teoria e prática na pesquisa com crianças: diálogos com William Corsaro. $1^{a}$ Ed. São Paulo: Editora Cortez, 2009.

MÜLLER, F. (Org.). Infância em perspectiva: políticas, pesquisas e instituições. $1^{\mathrm{a}}$. ed. São Paulo: Editora Cortez, 2010.

NASCIMENTO, M. L. et al (Orgs.). Infância e sociologia da infância: entre a invisibilidade e a voz: Relatório de pesquisa. 1ª Ed. São Paulo: FEUSP, 2013. 
OLIVEIRA, P. S. Vidas Compartilhadas:cultura e co-educação de gerações na vida cotidiana. São Paulo: Hucitec: Fapesp, 1999.

OLIVEIRA, Z. L. C.; RIBEIRO, P. M.; LONGO, L. Uma exploração inicial das informações sobre família no Censo Demográfico 2010. In.: Anais do XVIII Encontro Nacional de Estudos Populacionais (ABEP), Águas de Lindóia, 19 a 23 de novembro de 2012.

PANIAGUA, G.; PALACIOS, J. Educação Infantil: resposta educativa à diversidade. Porto Alegre: Armed, 2007.

PARR, Todd. O livro da família. 1ª Ed. São Paulo: Panda Books, 2003.

PARR, Todd. O livro da mamãe. $1^{a}$ Ed. São Paulo: Panda Books, 2007.

PARR, Todd. O livro da vovó. $1^{a}$ Ed. São Paulo: Panda Books, 2010.

PIMENTA, D. D. O desenho de meninas e meninos na Educação Infantil: um estudo sobre as relações de gênero na infância. Dissertação (Mestrado em Educação) - Escola de Filosofia, Letras e Ciências Humanas, Universidade Federal de São Paulo, Guarulhos, 2016.

PIRES, F. Ser adulta e pesquisar crianças: explorando possibilidades metodológicas na pesquisa antropológica. Revista de Antropologia, v. 50, n. 1, p. 225-270, jan./jun. 2007. Disponívelem: http://dx.doi.org/10.1590/S0034-77012007000100006Acesso em: 23.11.2017.

QVORTRUP, J. Nine theses about "childhood as a social phenomenon". Eurosocial Report Childhood as a Social Phenomenon: Lessons from an International Project, n. 47, p. 11-18, 1993.

ROSEMBERG, F. A educação da criança pequena, a produção de conhecimento e a universidade. Cadernos ANPED, n. 1, p. 57-64, 1989. Disponível em: http://repositorio.ufc.br/bitstream/riufc/10881/1/1987 art fmbrosemberg.pdfAcesso em: 01.11.2017.

ROSEMBERG, Fúlvia. A cidadania dos bebês e os direitos de pais e mães trabalhadoras. In: FINCO, D.; GOBBI, M. A.; FARIA, A. L. G. (Orgs.). Creche e Feminismo: desafios atuais para uma educação descolonizadora. Campinas: Edições Leituras Críticas, 2015. p. 163-183.

SARTI, C. A. Família patriarcal entre os pobres urbanos?. Caderno de Pesquisa, São Paulo, n.82, p. 37 41, ago. 1992. Disponível em: http://publicacoes.fcc.org.br/ojs/index.php/cp/article/view/981/991 Acesso em: 13.10.2017.

A família como ordem simbólica. Psicologia USP, São Paulo, v. 15, n. 3, p. 11-28., 2004. Disponível em: http://www.revistas.usp.br/psicousp/article/view/42289/45962 Acesso em: 13.10.2017. 
A família como espelho: um estudo sobre a moral dos pobres. São Paulo: Cortez, 2007.

SCOTT, J. W. Gênero: uma categoria útil de análise histórica. Educação \& Realidade. Porto Alegre, v.

20, n. $2, \quad$ p. 71-99, jul./dez.1995. Disponível em:
http://seer.ufrgs.br/index.php/educacaoerealidade/article/view/71721/40667 Acesso em: 11.11.2017.

SILVA, A. A. 'A fertilidade me sufoca' Maternidade, feminismo e creche: algumas interlocuções. In: FINCO, D.; GOBBI, M. A.; FARIA, A. L. G. (Orgs.). Creche e Feminismo: desafios atuais para uma educação descolonizadora. Campinas: Edições Leituras Críticas, 2015. p. 35-56.

THERBORN, G. Sexo e Poder:a família no mundo 1900-2000. São Paulo: Contexto, 2006.

THORNE. B. Feminism and the Family: two decades of thought. In.: THORNE. B.; YALOM, M. Rethinking Family: some feminist questions. Boston: NortheasternUniversity, 1992. p. 3-30.

VIANNA, C. RAMIRES, L. A eloquência do silêncio: gênero e diversidade sexual de família vinculados por livros didáticos. Psicologia Política. v. 8., n. 16, p. 345-362, jul/dez 2008. Disponível: http://pepsic.bvsalud.org/pdf/rpp/v8n16/v8n16a11.pdfAcessoem: 21.11.2017. 